\title{
The cultural dimension of environment: Ethnoscientific study on Santhal community in eastern India
}

\author{
Koustab Majumdar ${ }^{1}$ (D) . Dipankar Chatterjee ${ }^{1}$
}

Received: 3 August 2020 / Accepted: 4 November 2021 / Published online: 02 December 2021

(c) The Author(s) 2021

\begin{abstract}
This study explores the Santhal community to enhance the understanding of the human-nature relationship that fully captures distinct intricacies of ethnoecology. Relying on a qualitative research design, this study focuses on the perception and interpretation of environmental aspects using ethnoscientific methods among Santhals in West Bengal, India. It reveals that Santhals are still unique in perceiving the environment learned through folk models. Santhal's perception of environmental domains is constituted by various cognitive elements (resource distributions, care, feelings, attachment, myths, and superstitious credence toward their environment) and multifaceted interpretations (living beings, nonliving objects, natural and built environment). Based on its evidence, this study recommends that indigenous worldview-based ethnoscientific knowledge is the identity of indigenity that shapes ethnoscientific knowledge can be used in sustainable resource management practice. Furthermore, the study proposes a view that ignoring this unique ethnoscientific knowledge-based worldview base may degenerate the indigenous culture.
\end{abstract}

Keywords Culture $\cdot$ Environmental perception $\cdot$ Environmental change Ethnoscience $\cdot$ Santhals $\cdot$ India

Koustab Majumdar

koustab3662@gmail.com

1 Division of Rural and Tribal Development, Faculty of ARTD, Ramakrishna Mission

Vivekananda Educational and Research Institute, Morabadi, Ranchi, Jharkhand 834008, India 


\section{Background}

Indigenous people view both human beings and nature within a prolonged ecological family that reflects ancestry and origins. It is a recognition that exists in any environment is viable only when people view the lifestyles surrounding them as kin (Salmon 2000). There are approximately 370 million indigenous people throughout the world who represent more than 5000 diverse cultural backgrounds (United Nations 2009). Each indigenous community has a unique cultural system. Culture has been one of the fundamental factors in shaping and influencing worldviews, as human behaviour varies based on changing environmental conditions and contexts (Van Opstal and Hugé 2013). Indigenous people interact with the environment through their worldviews (Timoti et al. 2017). Indigenous people have a close relationship with the environment (Posey 1999; Maffi 2001; Altman et al. 2011; Grieves, 2009); therefore, natural and environmental resources such as forest, land, water, and sacred groves have not only been the identity of indigeneity but also their mode of existence (Dutta 2020). The indigenous way of perceiving natural elements as distinctive cultural practices offer an insightful human-environment relationship (Van Opstal and Hugé 2013) and environmental sustainability lessons (Tengö et al. 2017). However, policy-makers often neglect the importance of the ecological perceptuality of indigenous people in natural resource management at local, national, and international levels (Byg and Salick 2009, 166).

Indigenous people utilize indigenous knowledge or ethnoscientific knowledge (Stewart 2015) as a formal body of knowledge, which has gradually been developed through human history (Mazzocchi, 2006), and the process is never-ending. Indigenous people have retained their native ways of describing and interpreting nature, indigenous beliefs and practices in farming, medicine, and food gathering techniques (Majumdar and Chatterjee 2020). Studies (ex. Ulluwishewa et al. 2008) found that indigenous people are often highly dependent on natural resources. However, widespread contemporary degradation of natural resources pushes indigenous people, especially from the global south, in serious jeopardy to protect and conserve natural resources (Dutta 2020) that ultimately boost the loss of unique indigenous worldviews based on ethnoscientific knowledge as cultural practices. There has been increasing recognition of the worldviews of indigenous people at the global level, as it helps in managing and conserving agendas of environmental resources (Tengö et al. 2017). Nevertheless, it remains a challenging issue to implement customary worldview-based ethnoscientific knowledge to achieve ecological conservation goals (Houde 2007; Ens et al. 2015) due to technological progress in general and materialistic life and the anthropocentric and egoistic values of societies in particular.

Based on the issues, research findings, and recommendations mentioned above, we were motivated to embark on a foray or exploration of the ethnoscience of the Santhal community to examine and understand their perception related to different resources in the realized niche and some environmental issues that are affecting their lives and livelihood. In this study, we emphasize the following four aspects to construct the cultural dimension of the ecological resources of the Santhal community: 
1. Interpretative view of environment based on cultural consensus,

2. Intergenerational variation of environmental perception,

3. Perception of selected domains of environmental resources and

4. Recent environmental changes

This study will be useful in the sense that awareness of their ethnoscience as a sort of their rich indigenous knowledge may help members of the Santhal community that has been influenced and transformed by powerful or dominant majority groups regain their unique and distinctive cultural identity. Additionally, this may offer society vignettes of how indigenous groups have evolved and survived in the competitive world so that society may help them improve their way of living.

\section{Theoretical framework}

\section{Ethnoscience: conceptual definitions}

Ethnoscience was used as a means to study a culture. By examining the perceptions, knowledge and classifications of the world as reflected in the language of a culture, anthropologists gain better illumination or understanding of a given culture (Barnard and Spencer 2010). Barnard (2010, 254) mentioned that "Ethnoscience, or the 'New Ethnography', as it was often called in the 1960s, includes a set of methods for analyzing indigenous systems of classification, such as diseases, species of plants, or types of food." Stewart (2015) stated that "ethnoscience is a more technical form of two-word terms such as indigenous knowledge, native science, and many versions such as "African science," "Maori science,", etc. Ethnoscience can be conceptualized as a scientific approach (Rist and Dahdough 2006) to an ethnic community's perception of various facts of life. Ethnoscience fundamentally focuses on the worldviews of native people through which various social and natural phenomena are perceived and classified. Furthermore, ethnoscientific studies inclusively pivot on the cultural aspect. Culture is comprehended as the folk classification of society (Sturtevant 1964; Sengupta 2003; Wolff-Michael 2019). The folk classification is considered people's (Greek etho-) science, which recognizes the social and material world (Wolff-Michael 2019). Ethnoscientific knowledge is valid ecological knowledge that is "analogous to the knowledge derived through systematic scientific research. This process of deriving scientifically valid ecological knowledge through traditional means is called protoscience" (Chandler 1994, 415).

\section{Culture, perception, and environment: theoretical framework}

Culture is the determinant of individual perception that constructs human expectations, needs, and values (Markus and Kitayama, 1991) and influences an individual's perception (Kastanakis and Voyer, 2014). The varied perception that evolved into cultural settings also helps the person recognize their surrounding environment 


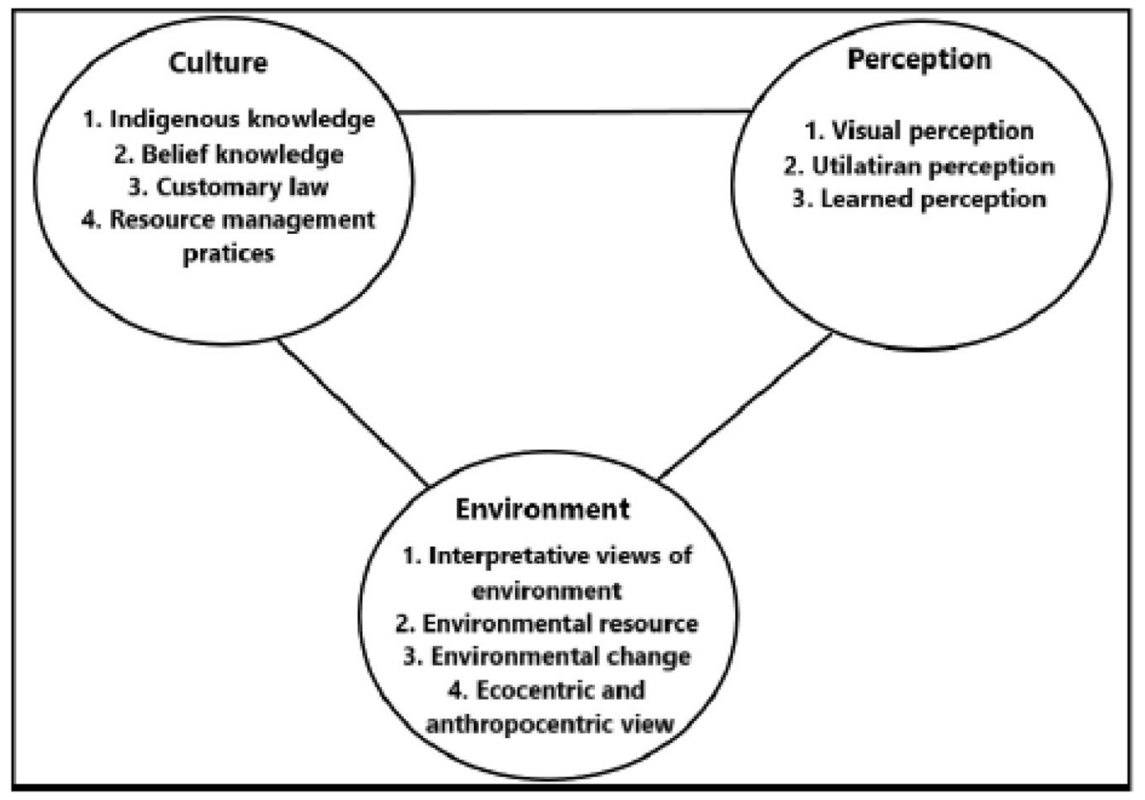

Fig. 1 Culture, perceptions and environment: theoretical framework. Source: Authors

(Weiner et al. 2003). The (environmental) worldviews ${ }^{1}$ that are rooted in culture (Peterson and Liu 2008) influence the attitudes of humans toward anthropogenic impacts on the environment (Wynveen et al. 2014). As an example, the empirical investigation of Schultz et al. (2000) suggested that culture is an essential determinant of environmental attitudes. Several scholars (Boeve-De Pauw and Van Petegem 2012) have reported that culture influences environmental worldviews. Xue et al. (2014) asserted that "cultural worldviews are potentially important determinants of environmental risk perceptions."

Humans acquire various culture-specific knowledge to categorize the surrounding environment. The categorization ability through indigenous perception, which is based on logic and indigenous knowledge (Bandyopadhyay 2000, 1), can be designated as the folk mode of cognition. This folk mode of cognition exclusively helps to recognize the environment as a discreet domain (Sengupta 2003). In this context, we strove to conceptualize and establish an explicit relationship in which this study was conducted (Fig. 1). The nature of the man-environment relationship is reciprocal, as both the environment and human beings have a profound influence on each other (Xaxa 1992, 101). Human beings perceive the environment in various ways, such as visual perceptions (through eyes), utilitarian perceptions (perceived through continuous utilization) and learned perceptions (perceived through learning), which direct the development of ecocentric or anthropocentric viewpoints toward the

\footnotetext{
1 The term 'worldview' can be defined as the 'person's value orientation' and his or her view of the cognized world (van Egmond \& de Vries, 2011, p. 855; Cited in Van Opstal and Hugé, 2013, p. 688).
} 
environment. In contrast, various subsets of culture (indigenous knowledge, belief system, customary law, resource management practices) that are transmitted from one generation to another strongly shape human perception. In addition, the (indigenous) worldviews (interpretative or descriptive views of the environment, environmental resource perceptions and environmental change perceptions) are the product of the complex interactions of culture and perception within the cognitive dimension of the human mind. In this context, this study tries to explore the logic, argument, and experimentation of the resource domains through their classification. Moreover, the analytical view of cultural terminologies based on an ethnoscientific approach will exhaustively reveal the fundamental cognitive world of the indigenous (Frake 1962, 75) community.

\section{Santhal community}

Santhal (also spelled 'Santal') is an ethnic group of eastern India (TEEB 2012). Santhal is one of the major tribal communities spread over West Bengal, Odisha, Assam and many other states in India. However, the population of Santhal people spreads over the districts of West Bengal, but they are highly found in Paschim Medinipur, Jhargram district, due to the high proliferation of forest areas. Traditionally, Santhal people were forest-dependent. During the British administration, the community shifted into agricultural occupation in pursuit of their livelihood (Jha 2009). The rice cultivation-based economy is the fundamental livelihood option for Santhals apart from the high dependency on natural/environmental (forest) resources. The Santhals of West Bengal can speak both Bengali and Santhali (traditional community-language $^{2}$ ). They are the followers of Sarna religion, which is the worship of naturebased gods; therefore, their culture is highly associated with nature/environment.

\section{Research method}

This study utilized a qualitative research design using ethnographic techniques to capture the ethnoscientific perspectives of the Santhal community. Qualitative research tends to include a small sample size to support the in-depth analysis of information to construct conclusions (Sandelowski 1996; Vasileiou et al. 2018). The qualitative research design was an appropriate method in this study, as this method explores the real world and social situation to understand the specific phenomenon (Bogdan and Biklen 1998). This study adopted the ethnoscience approach, which aims at revealing the structural principles of culture by utilizing ethnographic data analysis. Ethnoscientists mainly strive to understand how a specific group of people or community perceive and structure their environment through their native language (Howard and Janet 1992, 374).

\footnotetext{
${ }^{2}$ Santhali is the main traditional language of Santhals. However, they adopted local Bengali and communicate with other outsiders or community people.
} 
Three Santhal community-dominated villages (Nakuijhuri, Gutbani and Rangamatiya) with close geographical proximity in the Jhargram district of West Bengal, India, were selected for this study. A total of 53 key participants (aged between 15 years and 85 years) were interviewed purposively and voluntarily participated in the study to act as representatives in revealing and interpreting their culture (Moser and Korstjens 2018, 10). The participants were categorized into three groups (young age group [15-25 years], middle-aged group [26-59 years] and old age group [above 60 years]). Each age group denoted one generation.

The data were collected in three phases by the first author. The first phase was for a pilot survey. During the pilot survey, rapport building with the community members and testing of schedules were conducted. The primary data were collected in the second and third phases. Data were collected through four data collection tools: in-depth interviews (through open-ended pretested schedules), participant observations, folk taxonomy (through group discussions with selected participants) and focused group discussions (FGDs). In-depth interviews through open-ended schedules were employed to gather data regarding environmental perception and recent environmental change perception. ${ }^{3}$ Verbal consent was taken to record the response from participants during data collection. Each interview was conducted in a local language (Bengali) for 30 to $50 \mathrm{~min} .{ }^{4}$ Participants were ensured that their responses would be kept anonymous, and there would be no risk by participating in this study. After interviewing 53 participants, the data collection process was stopped due to the repetition of answers, and no new analytical information aroused; therefore, it indicated the data saturation point (Corbin and Strauss 2007; Moser and Korstjens 2018). Participant observations were conducted by participating in various festivals and cultural programmes, agricultural activities, forest resource collection and hunting. Folk taxonomy ${ }^{5}$ as an ethnoscience tool was employed through group discussions to explore the indigenous perceptions and structural classifications of selected domains (land, plant/forest, animal and water) of the environment within a culture (Sengupta 2003; Phaka 2019). A total of two FGDs were conducted with the participants (group consisted of 8 members with equal representation of males and females) of each age group to explore the contemporary environmental changes.

All the interviews were electronically recorded during the fieldwork and later transcribed (from Bengali to English) one by one by researchers. In the next stage, the transcripts were critically read, checked, analyzed and cross-checked at multiple rounds by two researchers and cross-checked by another. Then, we applied multiple rounds of inductive content analysis (Denzin and Lincoln 2005; Kyngäs 2020) to analyze the data to recognize the emerged key theme. The emerged theme represented the indigenous ethnoscientific knowledge of the Santhal community. The

\footnotetext{
3 We focused on perception of environmental change in last 20 years; therefore, pparticipants from middle and old age group only participated in FGDs on the environmental change.

${ }^{4}$ Shortest and lengthiest interview lasted for $30 \mathrm{~min}$ and $50 \mathrm{~min}$, respectively.

5 Distinct from scientific taxonomy, folk taxonomy is vernacular naming system usually generated from everyday social knowledge. It is a process through which the locally available resources are documented. Anthologists believe that the taxonomies are evolved through local socio-cultural systems and functions in the social system.
} 
mentioned quotes in the Results section were selected from the transcripts. The data of participant observations and FGDs were recorded through field notes. To ensure the credibility, transferability, and reliability of the data, the following measurements were employed: pilot testing of schedules through interviews, rigorous review of transcripts at each interview with the participants, cross-checking of the collected data, and collaboration with a Community Advisory Committee to verify our results (Castleden et al. 2009).

\section{Results}

The key results of the culturally constructed environment of the Santhals are presented into four mutually exclusive components: (i) interpretative views on environment; (ii) perceptuality and hierarchy of environmental resources; (iii) intergenerational variations of the perceptual environment; and (iv) perceptual nuances of environmental change.

\section{Interpretative views on environment}

Santhal's idea of the total reality of the environment was expressed by the term Disham. They perceived the environment as a total system that combines living beings or alive (Jiwit) and nonliving objects or dead (Goyet). Living elements that possess life can move and have growth factors. It included humans, animals, insects, birds, and plants. The non-living objects did not have life and growth factors and were immovable, such as all the material objects (house, road, and other constructed objects). They perceived the environment as a combination of natural and constructed elements. The Santhal view explicated that natural elements refer to all naturally evolved materials, and humans have no control over them; instead, spirits control natural elements. The natural elements included plants, sky, fire, water, plant resources, etc. Moreover, the constructed elements incorporated human-made materials such as houses, roads, and daily use instruments. However, various natural elements (sky, plants, fire, and water) and human-made items (dancing instrument [drum], different agricultural tools) were considered living due to the presence of religious, cultural and sacred values.

A (\#R31) middle-aged Santhal man elaborated:

All jiwit (living-being or alive) and goyet (nonliving or dead) are part of our disham (environment). My Ora (house) and the pond which is at the backside of my house; have no life but are part of our environment. However, hors (humans), tangris (animals), and even dares (plants) have lives.

Another old woman (\#R47) described:

The surrounding places include marangdare (large trees), doringdare (small trees), tangri (animals), Chede (birds), and Ora (house)... Some of them do not have life, and we cannot even control them like climate (rain, airflow, etc.). The climate and the land are the two most important parts of the environment because we are alive by using these. We cultivate with the help of climate and land resources. 
Environment-based rituals and cultural activities were determined by moments of natural calamity, movement of spirits, seasonal changes, climatic conditions and lunar changes. Various cultural and religious festivals (Sorhae, ${ }^{6}$ Sharul, ${ }^{7}$ Sarna $^{8}$ Mokor, ${ }^{9}$ Durgapuja ${ }^{10}$ ) at the Santhal Festival were intensely connected with nature. They were cautious in determining the space and time for performing these cultural and ritual activities. In terms of space, the rituals of religious festivals are performed in a specific sacred place called Jaher or Jaherthan. The natural order of time, such as seasonal changes, flowering, and fruiting of trees, was the determining factor of time for those festivals and rituals. Santhals believed that spirits can control the environment. There were two types of spirits: good spirit or Bonga and evil spirit or Bhoot bonga. Good spirits were responsible for all the good deeds and progress in socio-economic life. Thakur (priest) can satisfy good spirits through rituals. Santhals celebrated different cultural festivals (Bahaparab, ${ }^{11}$ Marangburu $^{12}$ ) to placate good spirits. While evil spirits always try to harm people. The Ojha (witch) can only control the evil spirits. According to Santhal myths, there was a robust totemic relationship between human beings and natural elements (especially birds and animals). Instead of a decent relationship, Santhals believed in totemic connections with animals and birds. The santhals were distributed in six different clans in the studied areas. Each clan was connected to various environmental elements, such as Baske (Stale rice), Tudu (Owl), Marandi (Weed), Hembram (Beetle nut), Kisku (Kingfisher) and Hasda (Goose). These clans had a distinctive set of traditional customs regarding food habits, worship and sacrifices ${ }^{13}$ (during rituals). However, there was a resilient community feeling among the clan members. Santhals were quite orthodox in conserving nature and environmental resources. They emphasized the sustainable use of environmental resources and conservation through customary

\footnotetext{
${ }^{6}$ Sorhae derived from the word "Sarhao" means thanksgiving. It is one of the famous festivals celebrated by Santhals. It is also known Cattle festival. During Hindu month of Kartik (October-November) This festival is celebrated in the honor of cattle (cow, goat and buffalo). It is celebrated to extend the gratitude to their livestock.

7 During the month of March-April when the new flowers come to tree, the Sharul festival is celebrated. They worship Sal tree as mother earth.

${ }^{8}$ Santhals are the followers of Sarna. In Sarna festival, they worship Sal tree in sacred groves. The area of worship is called Jaherthan.

${ }^{9}$ Mokor or Makar is celebrated in the month of January. It is the celebration of first harvest of paddy from agricultural field. During this festival, the Orabonga (house-god) is worshiped. Almost every households worship house-god and offer the newly harvest paddy. Consumption of liquor (Haria) is very common.

${ }^{10}$ Durgapuja is mainly adopted from the non-tribal population. Goddess Durga is considered as source of energy. During the month of September-October Durgapuja is celebrated. It is five long day festival. Santhals believe that worshiping Durga goddess will bestow them social progress and elevate the evil power.

11 Bahaparab is celebrated during the month of February-March (full-moon period). It is considered as flower festival as the emergence of spring.

12 Santhals consider Marangburu as the supreme deity. Marangburu as god is worshiped at Jaherthan. They worship Sal tree as the idol of Marangburu.

13 Santhals neither sacrifice (during rituals) nor kill (for the purpose of food) their respective totemic beings (i.e., animals or birds). They believe that killing the totemic being is equivalent to kill one's one member; therefore, it is considered as one of the greatest sins to the community.
} 
laws. Santhals considered the environment as a source of food, medicine (traditional medicines) and shelter; therefore, apart from the government enacting external laws, they adopted various customary resource conservation practices at the community level. One old-aged participant mentioned the significance of forest resources and conservation practices:

We love our forest. We highly use forest resources, so that it is our duty too to take care of it.... we prefer hunting, especially during any festivals. We do not use dense forest too much because it is a high source of natural resources. We need to take permission from the village forest committee to cut any trees during the financial crisis. We plant trees as per the instructions of our forest committee... forest resources will be exhausted if we continuously use them without conserving them. (\#R32).

Conventional resource management practices were based on traditional knowledge of the community. The natural world (all the natural elements including living beings and nonliving objects) was considered the supreme, and the human beings who evolved from nature were considered the ritual being of Santhal's worldviews.

\section{Perceptuality and hierarchy of environmental resources}

Santhal's view of the perceptual environment constituted various resources that were hierarchically organized based on utility. The community members conferred four types of perceived environmental resources, such as land, water, animal, and forest resources. The hierarchy of various perceived environmental resources was based on utilitarian value (Fig. 2). This finding indicated the importance of each domain of perceived environmental resources. Land, water, and plant/forest resources were designated natural resources, and animal resources were part of living beings. The perception and classification of these resources were based on the utilization of value perception. In terms of utilization value, land resources received the highest priority, followed by water resources, plants/forests, and animal resources. Subsistent agriculture was the primary livelihood of the Santhal community. Therefore, the land was considered a prominent environmental resource to the community and bestowed the highest-level preference. Water resources are used for drinking and essential aspects of agricultural practices and fish cultivation in community ponds. Community ponds are considered common property resources (CPRs). Animal resources secured the third rank as it was a prominent resource (bullock used in the agricultural field, cow's milk used to sell, and home consumption, egg, and poultrymeat are sold in the market for livelihood to the community people. Plant or forest resources were one of the most important environmental resources. Santhals are settled-agriculturists. However, they still significantly depend on forest resources. Plant/forest resources were not only designated livelihood support but were also an integral part of their social and cultural life. We discussed Santhal's perceived environmental resources: 
Fig. 2 Hierarchy of environmental resources

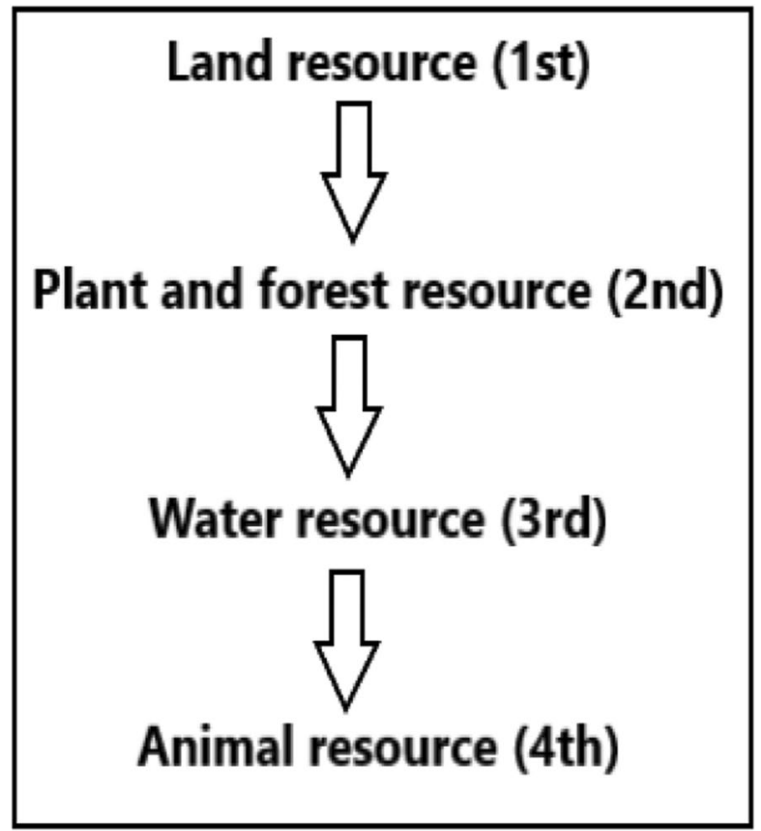

\section{Land resource}

Santhals termed land as Botre or Danga. They consider land to be the most crucial resource. A middle-aged male participant who engaged in agricultural practices for more than 20 years noted the following:

I have been cultivating my three acres of land. Since my childhood, I have been going to the agricultural field. My father taught me cultivation. I have been cultivating this land for a long time so that I do not want to be apart from this land. This land area gives us food and security. We consider land as our mother earth. I will be with it till my death. (\#R52).

The land as a whole was designated as part of community-owned land or village land (Atu botre), which was collectively utilized. This village land as a resource was classified into four categories: (a) agricultural land (Nuyabotre), (b) barren land (Nabotre), (c) grazing land (Puriyabotre), and (d) forestland (Birbotre). Agricultural land was the most productive land in which the community conducted agricultural activities (Chass). Based on the water retention capacity and slope, agricultural land was further categorized into two types: upland (Khotuboj/Khotubotre) and low land (Latarboj/Latarbotre).

Community people cultivated different types of seasonal vegetables (tomato, cauliflower, cabbage, and ladies-finger corn, pointed gourd, okra, bottle gourd, etc.) on uplands due to their high slope and low water retention capacity. The lowland (low slope and high water-retention capacity) was operated to cultivate paddies only during the rainy season. Community people did not cultivate barren land due to extremely low fertility. The barren land was utilized as a children's playground, 
constructing the house, and cultural festivals were conducted. The land where various domestic animals (cow, goat, bullock, etc.) browsed nominated as grazing land. Grazing land was the primary source of nutritious grass for domestic animals. The land areas belong to forests nominated as forestland. Forestland was the source of dry leaves and nontimber forest products and was also utilized for grazing domestic animals (bullock, buffalo, and goat).

\section{Plant and forest resources}

The Santhal community members perceived plant and forest resources as part of the living being. The plant grows on the soil (Hasa). They classified the physiological structure of plants into two sections: roots and stems. The visible portion that stays above the ground was nominated as a stem, and the invisible part below the ground was designated as the root. The plant resources were further classified based on the nature of woodiness and the spatial distribution of plant resources. The kind of woodiness defined the hardness of the stem. The community perceived three types of plants based on woodiness, such as grass, herb (Naddi- small size plants with leaves and woody trees (Dare- large trees). In terms of the distribution of plant resources, the plant resources surrounding home or habitat areas were designated local plants. Plant resources belonged to the forest referred to as forest plants. Based on cognitive and ethnoscientific knowledge, Santhals identified seven types of plants: edible plants (Jom dare), inedible plants (Bakojom dare), domesticated or local plants (Rohoy dare), wild plants (Bir dare), flowering plants (Baha dare), nonflowering plants (Banuonah dare), and poisonous plants (Gobojal dare). Notably, forest resources are the alternate source of livelihood for the community. They collect nontimber forest products, dry leaves, large woody trees, seasonal fruits and mushrooms, and medicinal plants. A young participant described the rarity of forest resources:

The market value of forest resources is too high. High-cost trees such as Sal are available in dense forest areas only. The nontimber fuelwood is sold to the local market. Our local $O j h a^{14}$ collects medicinal plants from dense forests, and woody trees are also available there. We can only cut high-cost trees according to our necessity if our forest committee allows. (\#R18).

The forest areas were classified into two groups, local forest and dense forest, based on the distribution of forest resources. Forest areas near Santhal habitat were considered local forest areas. People usually collect various forest resources (dry leaves, leafy vegetables, and non-timber forest products). While forest areas with a high concentration of trees were designated dense forests, these areas were rich sources of costly trees, ferocious animals, various medicinal plants, and high-protein edible mushrooms. The village forest committee (VFC) imposed a special law to secure dense forest areas due to their high value; therefore, community people can only harvest mushrooms, dry leaves, twigs, and selected medicinal plants. The VFC

\footnotetext{
14 Ojha is the local term which refers to the particular old person of the village. The person has extensive range of knowledge and experience in preparing medicines from locally available medicinal plants.
} 
was the central authority to review those customary rules and can punish the community members if accused of breaching the customary rules.

\section{(iii) water resources}

The Santhal community termed water as 'Dak'. They perceived water resources as an essential need of life. Water resources have dynamic utilization patterns in the community. Water resources were classified into types based on the source of availability, such as underground water and rainwater. One young participant mentioned the dynamic utilization of water resources:

Water is life for us. How can we survive without water? We Santhals are the farmer. We are dependent only on rainwater for rice cultivation that is sold to the market. Even we have to depend on underground water for drinking purposes, as we do not drink pond water. Water resources have various uses. (\#R43).

Underground water was utilized for irrigation (harvested through an electric motor pump during the summer season) for farms and drinking purposes (collected through the hand pump). Rainwater is stored in a community pond (Aher) and used for washing home utensils and clothes. Furthermore, the community pond was used for fish (Haku) cultivation. Well-water (Kunan) is often used for drinking and extensively used for domestic purposes. Santhals were very much concerned about the water conservation process by making dikes (Hir) and community ponds.

\section{(iv) animal resource}

Animal rearing was viewed as a supplementary source of income, as it minimizes the economically vulnerable condition of the community. Most of the Santhal households reared various domestic animals, such as cows (Dangri), buffalos (Bitkil), goats (Merom), chickens (Sim), ducks (Gede), pigs (Sukri) and dogs. Bullocks and cows were considered the supreme animals within Santhal culture due to their valuable contribution to agricultural activities. Bullock and buffalo are extensively used in the agricultural field, and cows are reared as domestic animals for milk. People intensely preferred to utilize the local breed of bullock and buffalo in the agricultural field due to its superior working capability. One young participant said:

We rear chicken, duck for meat, and egg. We sell eggs of chicken and duck and meat of pigs at the local market. We are very passionate about rearing dogs because dogs are immensely helpful in hunting forest animals such as wild pigs [Bir sukri], nonpoisonous snakes (Bir kud bing), and birds (wild chickens [Bir sim] and pigeons [Bir parwal]).

\section{Intergenerational variations of perceptual environment}

The intergenerational variations in the perceptual environment (Table 1) denoted that the young age group and the middle-aged group recognized the environment 


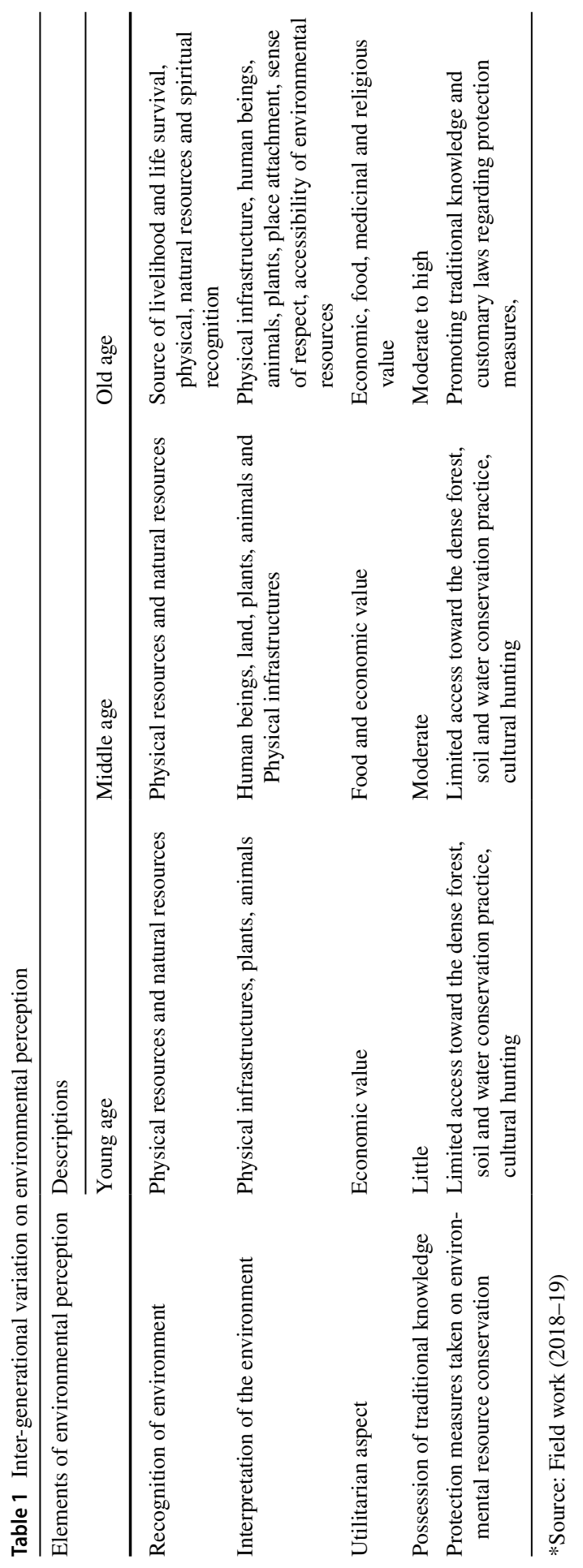


as a combination of physical and natural resources. The participants in the old age group recognized the environment, which includes all-natural and physical resources. Natural and physical resources were the sources of life survival and livelihood. The interpretative view of environmental perception revealed that age groups I and II reflected the same kind of view.

However, the middle-aged group included humans. However, the old age group additionally possessed a sturdy psychological connection (place attachment) with the surrounding environment. All environmental resource accessibility ensured the well-being of the members of the participants of the old age group. The utilitarian aspect of environmental perception varies across generations. The participants of the young age group perceived economic value. While the middle-aged group participants perceived economic and food value, the old age group perceived four-dimensional utilitarian value (economic, food, medicinal, and religious significance). The level of traditional knowledge varied across the age groups from least (young and middle-aged group) to high (old age group). The young and middle-aged group participants adopted protection measures toward the wild animals of dense forests to maintain the ecological balance. Nevertheless, the members of the older generation (old age group) were the moderators and promoters of conservation planning and implementation that are conducive to sustainable environmental resource utilization and management.

\section{Perceptual nuances of environmental change}

The perceptual nuances of environmental change (Table 2) outlined that erratic rainfall and late monsoon emerged as the very highly perceived environmental change reported by both age groups (middle and old age). The middle-aged community members mentioned the high level of pest infestation in the agricultural field. Agricultural fields (mainly rice and wheat fields) have been susceptible to wild elephant attacks for the last 10 years. A middle-aged participant shared his distinctive experience:

During my childhood, I saw an elephant roaming around the forest. They neither attack the village nor humans. However, I realize that the elephant attack is currently prominent. Why not? We have exhausted the forest resources and living in the condition of food unavailability; the elephant frequently attacks our rice field and often ferociously attacks our storeroom, house, and even brutally kills humans. (\#R41).

The participants from both ages (middle and old) groups said that rainfall could not be predicted as it was done during earlier times. Such changes were attributed to rapid environmental change. One old participant mentioned:

Earlier days I could read nature, I could predict the rainfall, I knew the exact location of growing medicinal plants and edible mushrooms varieties. The weather was not so hot so that I could work in the agricultural field for the whole day. Nevertheless, that weather has completely changed. (\#R53).

The fertility of the soil was reportedly low, and it resulted in poor crop productivity and production. However, people apply sufficient levels of chemical fertilizers and hybrid seeds. One young participant mentioned: 


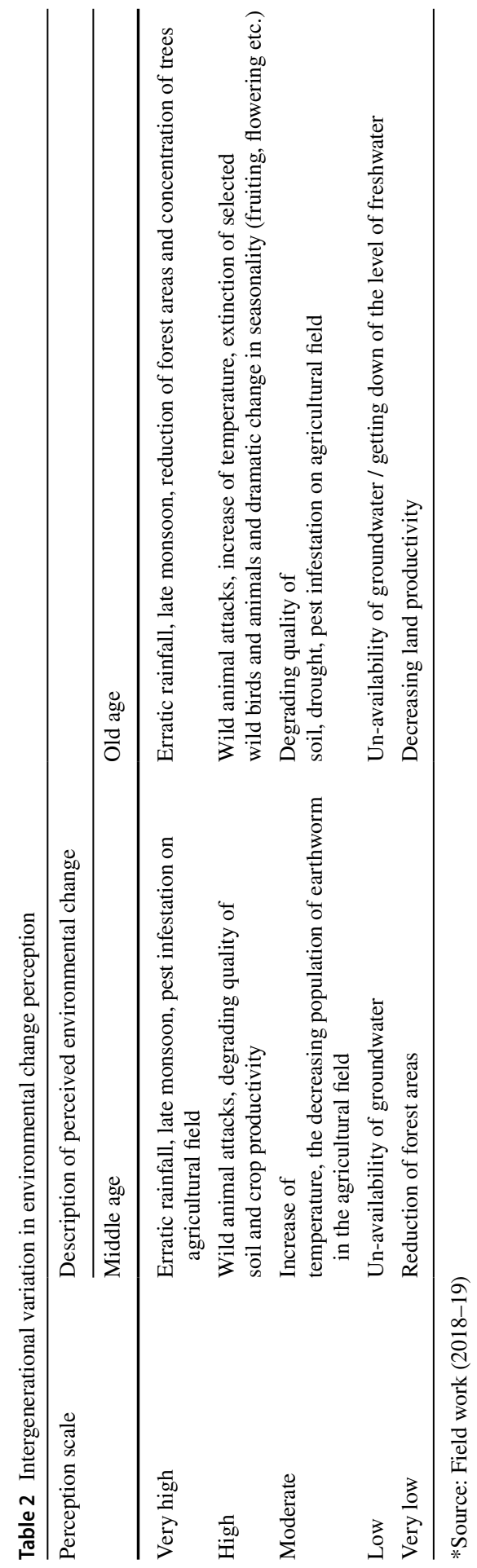


If we are late by a few days to spray the pesticides, a massive pest infestation may occur in the rice field that destroys our hard work and money. Sometimes, elephant destroys the entire rice field. Elephants attack the rice field as they do not get enough food in the forest. Even they attack our rice store attached to our home. Furthermore, these events are very recent. (\#R9).

Apart from it, the participants from the old age group highly perceived the increasing temperature and extinction of various wild birds and animals. A massive increase in temperature and the decreasing population of earthworms in the agricultural field was the moderate level perception reported by the middle-aged group. Old-aged participants mentioned the degrading quality of soil, drought, and intense pest infestation. The unavailability of groundwater was the least perceived. On the very least perception scale, the middle-aged group participants experienced a decreasing area of forest, and the old age group participants perceived low land productivity.

\section{Discussion}

Santhals categorize all the elements of the environment into two types: biological attributes (living beings and nonliving objects of the environment) and cultural attributes (natural environment and built environment). Constructive and analytical cognitive explanation of environment attributed to the interpretative account of environmental worldviews and ethnoscientific knowledge. It is attributed to visual perception. Santhal's environmental ethnoscientific knowledge-based worldviews are deeply related to culture. It is fascinating to note that the evolved culture is not only based on the natural environment but also involves the animal, which is considered an essential constituent of cultural elements through the totemic relationship. The traditional myths on the totemic relationship with nature permeate the social structure, customary law, marriage system, and therapeutic relationship (Mathur 2001). The environment as a whole has been the central point of Santhal's evolved culture and rituals. The interpretative stance of environmental worldviews is based on the belief system. This belief system implies the close juxtaposition of Santhal's culture with the environment/nature, supernatural world, and spirit world. The trilateral connectivity of Santhal's culture betokens the hypothesis of the nature-man-spirit complex (Vidyarthi 1963). The complicated relationship between Santhal's culture and nature can subtly be explicated as 'nature as culture' (Saraswati 2001).

The conventional resource management process, conservation practices through customary laws, and enduring respect to the nature of Santhals endorse the ecocentric view toward the environment and environmental resources- the interpretative views on environmental worldviews presented through environmental perception across generations. Environmental perception reveals a significant variation in the perceptual dimension of environmental worldviews. However, the participants of the young and middle-aged had a similar kind of perception concerning various perceptual elements of the environment. Young and middle-aged participants perceived the environment through visual attributes (resource distribution) and valuation of resources (economic value, food value). They possessed 
little to moderate levels of traditional knowledge that they utilized in livelihood and sustainable resource management processes. Old-age participants perceived and interpreted the environment as a source of life and livelihood apart from visual attributes. The utilitarian valuation included medicinal and religious values. The members of this age group who possessed a high level of traditional knowledge were fundamental role players in promoting protection measures regarding the environmental resource management process. The subjective environmental perception across three generations firmly contends that ethnoscientific knowledge is connected through sensory-perceptual aspects (dynamic utilization and distribution of resources, sense of respect, and intrinsic moral values toward ecocentric views), awareness, feelings, and care towards the environment and environmental resources (Rollero and Piccoli 2010).

Santhals have an impressive categorical distinction of numerous major environmental resources (land, plant/forest, water, and animal resources). The nuances of perceptions, hierarchical ranking, and further sub-classifications, including the verbal expressions of these major environmental resources, which are based on ethnoscientific knowledge and utilitarian value, are the product of utilitarian and learned perceptions (Sengupta 2003). The dynamic utilization of these perceived environmental resources is fundamentally determined by their cognitive structure at empirical, psychosocial, and cultural levels. It indicates a distinctive perception that describes and categorizes the various domains of the environment and living world with a sturdy logic, reflected by Santhals' unique culture, which evolved through the application of ethnoscientific knowledge. This uniqueness of the cognitive perception of environmental resources turns out to be a primordial continuum within Santhal's culture.

Connecting environmental change perceptions with worldviews unveiled culturally oriented (Shi et al. 2015) perceptions and superstitious beliefs toward contemporary environmental changes. The Santhals worldviews perceived environmental changes as the responses of the environment/nature itself against human exploitation toward the environment. Interestingly, it was evident from the findings that the old age population had more in-depth and clear environmental change perceptions than the younger age group (Lilian et al. 2008). For example, the participants from the old generation highly perceived the extinction of selected animals and birds. There were two-dimensional impacts of the perceived environmental changes on Santhal's life, i.e., impact on livelihood and culture. Poor-quality soil, fertility, crop production, massive pest infestation, wild animal attacks (elephants) on rice fields and erratic rainfall directly hamper livelihood. On the other hand, dramatic seasonal changes, including late monsoons, firmly influence the cultural calendar, as all cultural festivals and celebrations are based on natural phenomena. Santhals believe that changes in the cultural schedule ultimately madden all spirits and gods and result in various natural disasters. Furthermore, the perceived environmental change between two generations (the young and the middle-aged group) reveals a bright contrast in environmental change perceptions. The younger age group profoundly perceives an environmental change in the agricultural domain because of agriculture-based occupational dependence. However, the older age group perceived environmental change in the 
forest domain due to close association, recognition, and dependence on forest and forest resources.

\section{Conclusion}

The results revealed that environmental perception through ethnoscientific knowledge, interpretative views of surrounding the environment, environmental resource perceptions, and traditional resource management practices are deeply rooted in various socio-cultural and religious systems of practice among Santhals. Ethnoscientific knowledge was found to be constituted through various perceptual elements (surrounding environment, resource distributions, care, feelings, attachment, myths, and superstitious credence toward their environment) and multifaceted interpretations (living beings, non-living objects, natural and built environment). Notably, the Santhals perceive and interpret the environment as a cultural entity, where ethnoscientific knowledge operates as a bridge between the environment and culture. Most of the environmental elements (natural and built) had immense cultural significance and were linked to myths and superstitious beliefs (Mathur 2001). Some scholars (Byg and Salick 2009, 166) have suggested that scientists and policy-makers do not often consider indigenous perceptions and worldviews to be pertinent and equated with superstitious beliefs because of ethnocentric bias. However, the indigenous worldviews of Santhals that are orally transmitted from one generation to another as a cultural practice have the potential to provide a strong apposite and reliable information regarding environmental resource management practice and climate change for planned actions (Marin 2010). The worldviews reflect the ethnoscientific knowledge and generate the indigenous culture among the indigenous people, which is the identity of indignity, and, we neither deconstruct the indigenous culture without connecting the ethnoscientific knowledge nor separate the indigenous people from their distinctive perceptions over indigenous worldviews. It is a fact that ethnoscientific knowledge evolved through indigenous worldviews. The alienation of indigenous people from their culturally conditioned understanding and interpretation of the environment will undoubtedly degenerate their culture. Therefore, this study suggests that an ethnoscientific knowledge-based worldview should be considered in the policy-making process for the sake of endogenous development (forest resource management, community development) of indigenous communities.

Acknowledgements Authors are thankful to the participants for participating in the research. Authors are also thankful to all the community members for the excellent hospitability during the data collection process. Further, authors would like to register his gratitude for the valuable suggestions received from Govind Dhaske, Manoj Raul and two anonymous reviewers.

Informed consent Verbal consent was taken during the interview.

Authors' contributions KM author designed the study, did the fieldwork, data analysis, report writing, and drafted overall manuscript. DC analyzed data and review the manuscript. All authors read and approved the final manuscript. 
Funding Not applicable.

Availability of data and materials Not applicable.

\section{Declarations}

Ethical approval Ethical approval was granted by author's institution.

Competing interests All authors declare that they have no conflict of interest.

Open Access This article is licensed under a Creative Commons Attribution 4.0 International License, which permits use, sharing, adaptation, distribution and reproduction in any medium or format, as long as you give appropriate credit to the original author(s) and the source, provide a link to the Creative Commons licence, and indicate if changes were made. The images or other third party material in this article are included in the article's Creative Commons licence, unless indicated otherwise in a credit line to the material. If material is not included in the article's Creative Commons licence and your intended use is not permitted by statutory regulation or exceeds the permitted use, you will need to obtain permission directly from the copyright holder. To view a copy of this licence, visit http://creativecommons.org/licen ses/by/4.0/.

\section{References}

Altman, Jon, Seán Kerins, Janet Hunt, Emilie Ens, Katherine May, Susie Russell, and William Fogarty. 2011. Indigenous cultural and natural resource management futures. CAPER topical issue no. 9/2011, Australian National University, Canberra.

Bandyopadhyay, Soma. 2000. Folk classification of environmental resources and semantic categories of certain cultural practices an exploratory research on ethnoscience.

Barnard, Alan, and Jonathan, Spencer (eds). 2010. The Routledge encyclopedia of social and cultural anthropology. London: Routledge. https://doi.org/10.4324/9780203866474.

Boeve-De Pauw, Jelle, and Peter Van Petegem. 2012. Cultural differences in the environmental worldview of children. International Electronic Journal of Environmental Education, 2(1), 1-11.

Byg, Anja, and Jan Salick. 2009. Local perspectives on a global phenomenon. Climate change in eastern Tibetan villages. Global environmental change. 19:156-166. https://doi.org/10.1016/j.gloenvcha. 2009.01.010.

Castleden, Heather, Theresa Garvin, and Huu-ay-aht First Nation. 2009. Hishuk Tsawak (everything is one/connected): A Huu-ay-aht worldview for seeing forestry in British Columbia, Canada. Society and Natural Resources 22 (9): 789-804 https://doi.org/10.1080/08941920802098198.

Chandler, Paul. 1994. Adaptive ecology of traditionally derived agroforestry in China. Human Ecology. 22: 415-442 https://doi.org/10.1007/BF02169387.

Corbin, Juliet, and Anselm Strauss. 2007. Basics of qualitative research: Techniques and procedures for developing grounded theory. Sage Publications.

Denzin, Norman K., and Yvonna S. Lincoln, eds. 2005. The Sage handbook of qualitative research. Thousand Oaks, CA: Sage Publications.

Dutta, Uttaran. 2020. Protecting sacred-groves: Community-led environmental organizing by Santhals of eastern India. Environmental Communication, 14(1): 36-51 https://doi.org/10.1080/17524032.2019. 1585895.

Ens, Emilie J., Petina Pert, Philip A. Clarke, Marita Budden, Lilian Clubb, Bruce Doran, Cheryl Douras, et al. 2015. Indigenous biocultural knowledge in ecosystem science and management: Review and insight from Australia. Biological Conservation 181: 133-149. https://doi.org/10.1016/j.biocon. 2014.11.008.

Frake, Charles O. 1962. The ethnographic study of cognitive systems. In Anthropology and Human Behavior, T. Gadwin and W. Sturtevant (Eds.), 72-93. Washington D.C: Anthropological Society of Washington. 
Grieves, Vicki. 2009. Aboriginal spirituality: Aboriginal philosophy-The basis of Aboriginal social and emotional wellbeing. Discussion paper no. 9. Cooperative research Centre for Aboriginal Health: Casuarina, NT.

Healy, Alice F., Robert W. Proctor, and Irving B. Weiner. 2003. Handbook of psychology. New York: Wiley.

Houde, Nicolas. 2007. The six faces of traditional ecological knowledge: Challenges and opportunities for Canadian co-management arrangements. Ecology and Society 12 (2): 34. https://doi.org/10. 5751/ES-02270-120234.

Howard, Michael C., and Janet Dunaif-Hattis. 1992. Anthropology: Understanding human adaptation. New York: Harper Collins.

Jha, Amar Nath. 2009. Locating the ancient history of Santal Parganas. Proceedings of the Indian History Congress. 70: 185-196.

Kastanakis, Minas N., and Benjamin G. Voyer. 2014. The effect of culture on perception and cognition: A conceptual framework. Journal of Business Research 67 (4): 425-433.

Kyngäs, Helvi. 2020. Inductive content analysis. In The application of content analysis in nursing science research, ed. H. Kyngas, K. Mikkonen, and M. Kääriäinen, 13-21. Switzerland AG: Springer International Publishing. https://doi.org/10.1007/978-3-030-30199-6.

Maffi, Luisa. 2001. On biocultural diversity: Linking language, knowledge and the environment. Washington: Smithsonian Institution Press.

Majumdar, Koustab and Chatterjee, Dipankar. 2020. Tangible resources, intangible systems: A study on environmental perception among the Lodha community of West Bengal, India Journal of Indian Anthropological Society, 55: 218-234.

Marin, Andrei. 2010. Riders under storms: Contributions of nomadic herders' observations to analysing climate change in Mongolia. Global Environmental Change 20(1):162-176. https://doi.org/10. 1016/j.gloenvcha.2009.10.004.

Markus, Hazel R., and Shinobu Kitayama. 1991. Culture and the self: Implications for cognition, emotion, and motivation. Psychological Review 98 (2): 224-253 https://psycnet.apa.org/doi/10.1037/ 0033-295X.98.2.224.

Mathur, Nita (ed.). 2001. Santhal worldview. New Delhi: Concept Publishing Company.

Moser, Albine, and Irene Korstjens. 2018. Series: Practical guidance to qualitative research. Part 3: Sampling, data collection and analysis. European Journal of General Practice 24 (1): 9-18 https://doi. org/10.1080/13814788.2017.1375091.

Lilian (Na'ia) Alessa, Andrew (Anaru) Kliskey, Paula Williams, and Michael Barton. 2008. Perception of change in freshwater in remote resource-dependent Arctic communities, Global Environmental Change, 18(1): 153-164. https://doi.org/10.1016/j.gloenvcha.2007.05.007.

Peterson, M. Nils, and Jianguo Liu. 2008. Impacts of religion on environmental worldviews: The Teton Valley case. Society and Natural Resources 21 (8): 704-718.

Phaka, Fortunate M., Edward C. Netherlands, Donnavan JD Kruger, and Louis H. Du Preez. 2019. Folk taxonomy and indigenous names for frogs in Zululand, South Africa. Journal of Ethnobiology Ethnomedicine. 15(1): 17. https://doi.org/10.1186/s13002-019-0294-3.

Posey, DA. 1999. Cultural and spiritual values of biodiversity. United Nations environment Programme: Nairobi, Kenya, and intermediate technology: London.

Religious Beliefs and Practices among the Santals, New Delhi: Manohar Publications n.d..

Rist, Stephan, and Farid Dahdouh-Guebas. 2006. Ethnosciences-A step towards the integration of scientific and indigenous forms of knowledge in the management of natural resources for the future. Environment, Development and Sustainnability 4 (8): 467-493 https://doi.org/10.1007/ s10668-006-9050-7.

Rollero, Chiara, and Norma De Piccoli. 2010. Place attachment, identification and environment perception: An empirical study. Journal of Environmental Psychology. 30 (2): 198-205 https://doi.org/10. 1016/j.jenvp.2009.12.003.

Salmón, Enrique. 2000. Kincentric ecology: Indigenous perceptions of the human-nature relationship. Ecological Applications 10 (5): 1327-1332 https://doi.org/10.1890/1051-0761(2000)010[1327: KEIPOT]2.0.CO;2.

Sandelowski, Margarete. 1996. One is the liveliest number: The case orientation of qualitative research. Research in Nursing \& Health 19 (6): 525-529 https://doi.org/10.1002/(sici)1098-240x(199612) 19:6\%3C525::aid-nur8\%3E3.0.co;2-q.

Saraswati, B.N. 2001. Nature as culture: The vision of a tradition. In Santhal worldview, Nita Mathur (Ed.), 1-7. New Delhi: Concept Publishing Company. 
Schultz, P. Wesley, John B. Unipan, and Raymond J. Gamba. 2000. Acculturation and ecological worldview among Latino Americans. The Journal of Environmental Education 31 (2): 22-27 https://doi. org/10.1080/00958960009598635.

Sengupta, Shyamalkanti. 2003. Folk perception of environment. Kolkata: Classique Books.

Sengupta, Shyamalkanti, and Soma Bandyopadhyay. 1997. Concept of environment and folk taxonomy: The case of the Juango, the ho and the Santal. Bulletin of the cultural research institute, West Bengal, XIX(I): 15-22.

Shi, Jing, Vivianne HM Visschers, and Michael Siegrist. 2015. Public perception of climate change: The importance of knowledge and cultural worldviews. Risk Analysis 35: 2183-2201. https://doi.org/10. 1111/risa.12406.

Stewart, Georgina Marjorie. 2015. Ethnoscience. In Encyclopedia of science education, ed. R. Gunstone. Dordrecht: Springer.

Sturtevant, William C. 1964. Studies in Ethnoscience 1. American Anthropologist 66 (3): 99-131 https:// doi.org/10.1007/978-94-007-2150-0.

Tahi. 2017. A representation of a Tuawhenua worldview guides environmental conservation. Ecology and Society 22 (4): 20 https://doi.org/10.5751/ES-09768-220420.

TEEB [The Editors of Encyclopedia Britannica]. 2012. Santhal. Retrieved on $15^{\text {th }}$ April, 2020 from https://www.britannica.com/topic/Santhal.

Tengö, Maria, Rosemary Hill, Pernilla Malmer, Christopher M. Raymond, Marja Spierenburg, Finn Danielsen, Thomas Elmqvist, and Carl Folke. 2017. Weaving knowledge systems in IPBES, CBD and beyond-Lessons learned for sustainability. Current Opinion in Environmental Sustainability 26-27: 17-25 https://doi.org/10.1016/j.cosust.2016.12.005.

Timoti, Puke, Philip O’B. Lyver, Rangi Matamua, Christopher J. Jones, and Brenda L n.d..

Ulluwishewa, Rohana, Nick Roskruge, Garth Harmsworth, and Bantong Antaran. 2008. Indigenous knowledge for natural resource management: A comparative study of Māori in New Zealand and Dusun in Brunei Darussalam. GeoJournal 73: 271-284 https://doi.org/10.1007/s10708-008-9198-9.

Van Opstal, Maarten, and Jean Hugé. 2013. Knowledge for sustainable development: A worldviews perspective. Environment, Development and Sustainability ,15:687-709. https://doi.org/10.1007/ s10668-012-9401-5.

Vidyarthi, Lalita. Prasad. 1963. The Maler: A study in nature-man-spirit complex of a hill tribe in Bihar. Bookland.

Wolff-Michael, Roth. 2019. Ethnoscience. In Paul Atkinson, Sara Delamont, Alexandru Cernat, Joseph W. Sakshaug \& Richard a. Williams (Eds.), SAGE research methods foundations. https://doi.org/10. 4135/9781526421036744802.

Wynveen, Christopher J., Gerard T. Kyle, and Stephen G. Sutton. 2014. Environmental worldview, place attachment, and awareness of environmental impacts in a marine environment. Environment and Behavior 46 (8): 993-1017.

Xaxa, Virginius. 1992. Oraons: Religion, customs and environment. India International Centre Quarterly 19 (1-2): 101-110.

Xue, Wen, Donald W. Hine, Natasha M. Loi, Einar B. Thorsteinsson, and Wendy J. Phillips. 2014. Cultural worldviews and environmental risk perceptions: A meta-analysis. Journal of Environmental Psychology 40: 249-258.

United Nations. 2009. State of the World's Indigenous Peoples. United Nations publications: New York.

Van Opstal, Maarten, and Jean Hugé. 2013. Knowledge for sustainable development: A worldviews perspective. Environment, Development and Sustainability, 15: 687-709. https://doi.org/10.1007/ s10668-012-9401-5.

\section{Comments}

Publisher's Note Springer Nature remains neutral with regard to jurisdictional claims in published maps and institutional affiliations. 